\title{
Editorial
}

\section{Heat shock: a barrier to hepatic ischemic injury}

\author{
José M. Mato*, Fernando J. Corrales, Matias A. Avila \\ Department of Medicine, Universidad de Navarra, Pamplona, Spain
}

See Article, pages 619-627

The interruption of tissue oxygenation - ischemia - is probably the most important problem associated with liver surgery [1,2]. This is especially true for patients with impaired liver function, such as liver cirrhosis or steatosis, where the effects of ischemic injury may be irreversible even if the duration of the interruption of blood flow is short. Paradoxically, the generation of reactive oxygen species (ROS) seems to be a key factor in the development of liver damage in irreversible ischemia. The answer to this apparent paradox lies in that ROS are generated not during the initial period of ischemia but upon restoration of blood flow or reperfusion. During ischemia, a variety of cellular and molecular events take place in the liver that, upon reoxygenation, result in the massive production of ROS, which inflict direct tissue damage and initiate a cascade of deleterious cellular responses leading to inflammation, cell death, and organ failure. The term ischemia-reperfusion (IR) injury has been coined to indicate this condition. Therapeutic strategies aimed to prevent IR injury are focused on controlling ROS generation at the time of restoration of blood flow or reperfusion, and intervening in the signal cascade initiated by reoxygenation.

Liver injury induced by hepatic IR is characterized by activation of the transcription factor NF- $\mathrm{B}$, activation of Kupffer cells, increased production of proinflammatory cytokines, such as tumour necrosis factor- $\alpha$ (TNF- $\alpha)$ and interleukin-1 (IL-1), liver polymorphonuclear (PMN) leukocyte activation and infiltration, and hepatocellular damage [2]. TNF- $\alpha$ is an important mediator in PMN leukocyte recruitment and activation which in turn are a potent source of ROS. In view of this critical role played by TNF- $\alpha$ in liver injury, it has been long proposed that suppression of TNF- $\alpha$ production may attenuate liver injury after IR. Thus, anti-TNF- $\alpha$ antibodies [3] and suppression of cytokine generation with FR167653 [4] decrease hepatic IR injury in experimental models.

\footnotetext{
* Corresponding author.

E-mail address: jmmato@unav.es (J.M. Mato).
}

Recent studies indicate that Kupffer cells play a key role in the generation of TNF- $\alpha$ during IR liver injury [5]. For instance, the inhibition of TNF- $\alpha$ release from Kupffer cells with gadolinium chloride $\left(\mathrm{GdCl}_{3}\right)$, previous to the IR treatment, maintained low levels of TNF- $\alpha$ attenuating liver injury, an effect that could be reverted by the administration of exogenous TNF- $\alpha$ [6,7]. In addition to $\mathrm{GdCl}_{3}$, and other inhibitors of Kupffer cell activation, a variety of different pharmacological approaches, such as the administration of adenosine [8], nitric oxide donors [9], and antioxidants $[10,11]$, have been successfully applied in animal models to attenuate liver injury after IR. Identifying the mechanisms of action by which these and other agents provide ischemic tolerance will provide potential targets for the development of new treatments for IR liver injury.

It is known for many years that cellular injury, independently of its nature (infectious, oxygen deprivation, inflammatory, heat, etc.), induces an adaptive response. Accordingly, another therapeutic strategy aimed to ameliorate hepatic IR injury consists in the exposure of the liver to brief periods of blood flow interruption followed by reperfusion prior to the prolonged IR treatment, a procedure that is know as ischemic preconditioning. The protective effects of ischemic preconditioning were first described in the myocardium and have been also shown experimentally in the liver. It has been recently demonstrated that ischemic preconditioning protects sinusoidal endothelial cells and suppresses Kupffer cell activation after storage and reperfusion [12].

Heat shock proteins (HSPs) are well known as cytoprotective proteins. Accordingly, different groups have investigated whether a period of hyperthermia followed by recovery from this heat treatment is another mechanism for acquiring ischemic tolerance. Heat shock pretreatment has been shown to prevent hepatic ischemic injury caused by Pringle's manoeuvre [13] and in an isolated rat liver perfusion model [14]. Heat shock preconditioning has been also shown to reduce liver injury induced by carbon tetrachloride administration [15] and to improve liver trans- 
plant survival in rats [16]. Moreover, geranylgeranylacetone (GGA), a heat shock protein inducer, has been recently shown to prevent primary graft malfunction in a model of rat liver transplantation [17]. Since GGA is a non-toxic antiulcer drug, it has been proposed that oral administration of this agent may be useful in preventing IR liver injury [17]. In this model of liver transplantation, GGA pretreatment increased the hepatic mRNA levels of HSP72 and HSP 90 and reduced the serum levels of TNF- $\alpha$ after reperfusion (17), suggesting that heat shock preconditioning induces ischemic tolerance acting directly through the liver. In this issue of the Journal, Yonezawa and colleagues [18] demonstrate that hyperthermic preconditioning attenuates IR liver injury acting at the organ level through the suppression of Kupffer cell activation and neutrophil infiltration, while providing a protective effect on the parenchymal cells.

The authors first found that heat shock preconditioning markedly induced HSP72 expression in the different types of cells that exist in the liver -hepatocytes, Kupffer cells and endothelial cells. Then, they observed that the increase in plasma TNF- $\alpha$ and in hepatic TNF- $\alpha$ mRNA during reperfusion was significantly suppressed by heat shock preconditioning. In these experiments, Yonezawa and colleagues immersed a group of rats in a hot water bath for $15 \mathrm{~min}$ to maintain their rectal temperature at $42^{\circ} \mathrm{C}$. The control group of rats was immersed in a bath maintained at $37^{\circ} \mathrm{C}$ for the same period of time. After $48 \mathrm{~h}$ recovery, partial hepatic ischemia was induced by clamping the vessels of the left hepatic lobes; and after a $90 \mathrm{~min}$ ischemia, the vessels were unclamped. Plasma was collected and the left lobes of the livers were removed before clamping, at reperfusion and at various times after reperfusion. They also found that the increase in plasma alanine amino transferase (ALT) levels during the reoxygenation period was less marked in the heat shock pretreated animals than in the control rats. Histological examination of the livers confirmed that heat shock pretreatment preserved the tissue integrity during reperfusion. The production of cytokine-induced neutrophil chemoattractant, a potent chemoattractant for neutrophils in rats, was also suppressed in the heat shock pretreated animals. Consistently, while reperfusion induced an intense infiltration of PMNs in the hepatic parenchyma of the control group, particularly in necrotic areas, in the heat shock pretreated group the number of PMNs was smaller and were only found in the hepatic triad.

In summary, the studies of Yonezawa and colleagues demonstrate that the stress produced by hyperthermic preconditioning induces tolerance to a future ischemic insult acting directly on the various cell types of the liver - hepatocytes, Kupffer cells and endothelial cells. But how does heat shock preconditioning works its protective effect on liver cells? One possibility is that HSP72, the major heat shock protein, may prevent Kupffer cells from activation in response to IR injury by suppressing NF- $\kappa \mathrm{B}$ activation. NF$\kappa \mathrm{B}$ is normally kept in an inactive state outside the nucleus by its binding partner, I-кB. Phosphorylation of this inhibi- tor by the $\mathrm{I}-\mathrm{kB}$ kinases leads to its degradation and the release of NF- $\mathrm{KB}$, which can then migrate to the nucleus and activate target genes. Although Yonezawa and colleagues did not determine NF- $\kappa$ B activation or I- $\kappa$ B phosphorylation in their experimental model, different studies indicate that hyperthermia suppresses I- $\mathrm{kB}$ phosphorylation and NF- $\kappa \mathrm{B}$ activation in a variety of cellular systems including astroglial cells, RAW 264.7 murine macrophages, rat and human islets, murine lung epithelium and rat hepatocytes [19-23]. Recently, Frossard and colleagues have demonstrated that hyperthermia in rats decreases the severity of cerulein-induced pancreatitis by reducing $\mathrm{TNF} \alpha$ expression in the pancreas through the stabilization I- $\kappa \mathrm{B}$ and the suppression of NF- $\mathrm{KB}$ activation [24]. Suppression by heat shock preconditioning of NF- $\mathrm{KB}$ activation in response to IR may be then the mechanism by which the production of TNF- $\alpha$ from Kupffer cells is inhibited. The reduced production of TNF- $\alpha$ by Kupffer cells in response to IR after heat shock preconditioning will reduce, in its turn, the cytotoxic effect of this cytokine on the hepatocytes (which depends also on the activation of NF-кB), limit the infiltration of PMNs to the liver and ameliorate tissue damage.

Based on these studies about how heat shock preconditioning protects the liver from IR injury, Yonezawa and colleagues propose that, although hyperthermia is still an experimental treatment, patients undergoing liver surgery may benefit from the future improvement of extracorporeal local hyperthermic technologies using, for instance, radio frequency irradiation. However, as reviewed recently by DeMeester and colleagues [25], it should be remembered that when cells or animals have been previously 'primed' by exposure to endotoxins a subsequent heat stress may precipitate cell death by apoptosis - a phenomenon which has been named 'the heat shock paradox' [25]. Therefore, a clear understanding of the signaling pathways activated by heat shock and inflammation and how these stress responses interact seems necessary before evaluation of the therapeutic potential of hyperthermia.

\section{References}

[1] Hui AM, Kawasaki S, Makuuchi M, Nakayama J, Ikegami T, Miyagawa S. Liver injury following normothermic ischemia in steatotic rat liver. Hepatology 1994;20:1287-1293.

[2] Serracino-Inglott F, Habib NA, Mathie RT. Hepatic ischemia-reperfusion injury. Am J Surg 2001;181:160-166.

[3] Colletti LM, Remick DG, Burtch GD, Kunkel SL, Strieter RM, Campbell Jr DA. Role of tumour necrosis factor-alpha in the pathophysiologyc alterations after hepatic ischemia/reperfusion injury in the rat. J Clin Invest 1990;85:1936-1943.

[4] Hato S, Urakami A, Yamano T, Uemura T, Ota T, Hirai R, Shimizu N. Attenuation of liver and lung injury after hepatic ischemia and reperfusion by a cytokine-suppressive agent, fr167653. Eur Surg Res 2001;33:202-209.

[5] Wanner GA, Ertel W, Muller P, Hofer Y, Leiderer R, Menger MD, Messmer K. Liver ischemia and reperfusion induces a systemic 
inflammatory response through Kupffer cell activation. Shock 1996;5:34-40.

[6] Peralta C, Prats N, Xaus C, Gelpi E, Rosello-Catafau J. Protective effect of liver ischemic preconditioning on liver and lung injury induced by hepatic ischemia-reperfusion in the rat. Hepatology 1999;30:1481-1489.

[7] Mosher B, Dean R, Harkema J, Remick D, Palma J, Crockett E. Inhibition of Kupffer cells reduced cxc chemokine production and liver injury. J Surg Res 2001;99:201-210.

[8] Todo S, Zhu Y, Zhang S, Jin MB, Ishizaki N, Tanaka H, Subbotin V, Starzl TE. Attenuation of ischemic liver injury by augmentation of endogenous adenosine. Transplantation 1997;63:217-223.

[9] Liu P, Xu B, Spokas E, Lai PS, Wong PY. Role of endogenous nitric oxide in TNF-alpha and IL-1beta generation in hepatic ischemiareperfusion. Shock 2000;13:217-223.

[10] Koeppel TA, Lehmann TG, Thies JC, Gehrcke R, Gebhard MM, Herfarth $\mathrm{C}$, et al. Impact of $\mathrm{N}$-acetylcysteine on the hepatic microcirculation after orthopic liver transplantation. Transplantation 1996;61:1397-1402.

[11] Dunne JB, Alexander B, Williams R, Tredger JM. Evidence that $S$ adenosyl-L-methionine diastereoisomers may reduce ischaemiareperfusion injury by interacting with purinoceptors in isolated rat liver. Br J Pharmacol. 1998;125:225-233.

[12] Arai M, Thurman RG, Lemasters JJ. Ischemic preconditioning of rat livers against cold storage-reperfusion injury: role of nonparenchymal cells and the phenomenon of heterologous preconditioning. Liver Transpl 2001;7:292-299.

[13] Saad S, Kanai M, Awane M, Yamamoto Y, Morimoto T, Isselhard W, et al. Protective effect of heat shock pretreatment with heat shock protein induction before hepatic warm ischemic injury caused by Pringle's manoeuvre. Surgery 1995;118:510-516.

[14] Terajima H, Enders G, Thiaener A, Hammer C, Kondo T, Thiery J, et al. Impact of hyperthermic preconditioning on postischemic hepatic microcirculatory disturbances in an isolated perfusion model of the rat liver. Hepatology 2000;31:407-415.

[15] Yamamoto H, Yamamoto Y, Yamagami K, Kume M, Kimoto S,
Toyokuni S, et al. Heat-shock preconditioning reduces oxidative protein denaturation and ameliorates liver injury by carbon tetrachloride in rats. Res Exp Med 2000;199:309-318.

[16] Matsumoto K, Honda K, Kobayashi N. Protective effect of heat preconditioning of rat liver graft resulting in improved transplant survival. Transplantation 2001;71:862-868.

[17] Fudaba Y, Ohdan H, Tashiro H, Ito H, Fukuda Y, Dohi K, Asahara T. Geranylgeranylacetone, a heat shock protein inducer, prevents primary graft non-function in rat liver transplantation. Transplantation 2001;71:184-189.

[18] Yonezawa K, Yamamoto Y, Yamamoto H, Ishikawa Y, Uchinami H, Taura K, et al. Suppression of tumor necrosis factor- $\alpha$ production and neutrophil infiltration during ischemia-reperfusion injury of the liver after heat shock preconditioning. J Hepatol 2001;35:619-627.

[19] Feinstein DL, Galea E, Aquino DA, Li GC, Xu H, Reis DJ. Heat shock protein 70 suppresses astroglial-inducible nitric oxide synthase expression by decreasing NFkappaB activation. J Biol Chem 1996;271:17724-17732.

[20] Shanley TP, Ryan MA, Eaves-Pyles T, Wong HR. Heat shock inhibits phosphorylation of I-kappaBalpha. Shock 2000;14:447-450.

[21] Scarim AL, Heitmeier MR, Corbett JA. Heat shock inhibits cytokineinduced nitric oxide synthase expression by rat and human islets. Endocrinology 1998;139:5050-5057.

[22] Wong HR, Ryan M, Wispe JR. The heat shock response inhibits inducible nitric oxide synthase gene expression by blocking $\mathrm{I}$ kappa-B degradation and NF-kappa B nuclear translocation. Biochem Biophys Res Commun 1997;231(2):257-263.

[23] de Vera ME, Kim YM, Wong HR, Wang Q, Billiar TR, Geller DA. Heat shock response inhibits cytokine-inducible nitric oxide synthase expression in rat hepatocytes. Hepatology 1996;24:1238-1245.

[24] Frossard JL, Pastor CM, Hadengue A. Effect of hyperthermia on NFkappaB binding activity in cerulein-induced acute pancreatitis. Am J Physiol Gastrointest Liver Physiol 2001;280:G1157-G1162.

[25] DeMeester SL, Buchman TG, Cobb P. The heat shock paradox: does NF-кB determine cell fate? FASEB J 2001;15:270-274. 